\title{
Gloria Sutton
}

\section{The Politics of Breath: Reanimating the Air Art of Hans Haacke and Lygia Clark as Models of Social Critique}

As part of their distinct, and manifestly influential bodies of work, artists Hans Haacke (b. 1936) and Lygia Clark (1920-1988), produced indelible artworks that engendered a fragile balance between air, the inorganic materials used to suspend or generate it, and the human bodies that impacted it. These works modeled the precarious relationship humans have with their environments: natural, technological, biological and social. Haacke's and Clarke's early investment in aligning kinetic processes alongside organic/biological and human/social ones presents an integrated system of transference - what can be thought of as a reciprocity between bodies of knowledge production and bodies breathing in real time and in real space. Installed in their retrospective exhibitions in New York - Clark's The Abandonment of Art at the Museum of Modern Art (2014) and Haacke's All Connect$e d$ at the New Museum (2019) - these air art works first produced in the 1960s were re-staged against a more contemporary socio-political backdrop marked by the continued struggle for social justice reform stemming from the civil rights movements that defined the period of their initial making. Examined together here, selected works by Haacke and Clark pivot on notions of reflexivity and complicity - reanimating our understanding of the interconnectedness of visual art and cultural life in a manner that draws our attention to the politics of breath within contemporary art.

From Empathy to Complicity: Haacke's Early Systems Works An innocuous $30.5 \times 30.5 \times 30.5 \mathrm{~cm}$ clear acrylic container, Haacke's Large Condensation Cube (1963-1967) was positioned on the floor of New York's New Museum throughout the Fall of 2019 as part of the 
New York-based German artist's first U.S. retrospective in over thirty years. A small amount of distilled water - injected through a micro slit in the otherwise sealed transparent box - pooled along the bottom edge. Over the days, weeks and months of the exhibition's run, the temperature inside the Cube constantly reacted to its external pressures including overhead spotlights, the museum's central air conditioning, and the fluctuation of ambient room temperature as viewers flowed in and out of the galleries. Among the least controllable aspects of the socalled clean space of the museum was the release of carbon dioxide as visitors inhaled the already re-circulated air and then breathed it back out through their own biological HVAC mechanisms. ${ }^{1}$ The relative difference between the Cube's interior and exterior temperatures caused the $1 \mathrm{~cm}$ high horizontal line of water to evaporate and form tiny droplets on the inside lid (Fig. 1). These drops coalesced into larger formations until the volume's collective weight overpowered the forces of adhesion and thin traces of water began to run down the sides and regrouped along the bottom again. While visitors passively observed the enclosed microclimate occurring in the $\mathrm{Cube}$, their whispers and muted conversations in the gallery space amplified the carbon dioxide in the room mixing with what art historian Caroline A. Jones described as the very human "inputs" which over time would have impacted the relative dew point and atmospheric saturation levels of Haacke's Cube. ${ }^{2}$ While it was impossible to immediately see the influence the visitors' bodies had on the condensation process while standing in front of the work - fluctuations in the room's humidity levels could be registered by hygrothermographs, typically installed in museums to protect artworks from moisture. ${ }^{3}$ Thus, the Cube - purposefully devoid of style, gesture, or affect - is not a representation, but an incontrovertible marker of corporeal presence in the museum. Human 'inputs' mix with natural systems and shape the graceful veil of air and water that slowly and almost imperceptively animated the Cube's clear surfaces. The Cube may have

1 For a close reading of how Haacke's Condensation Cube intersects with modern architectural histories of the mechanization of heating and cooling systems as well as developments in museological climate engineering in a manner that lays out the differences between modernism and postmodern ideology see Mark Jarzombek, "Haacke's Condensation Cube: The Machine in the Box and the Travails of Architecture," in: Thresholds 30, 2005, pp. 98-103.

2 Caroline A. Jones, "Hans Haacke 1967," in: Caroline A. Jones (ed.), Hans Haacke 1967, exh. cat. MIT List Visual Arts Center, Cambridge, Massachusetts 2011, pp. 7-27, here: p. 13.
3 In a 2009 interview, Jones pressed Haacke to acknowledge that the presence of a hygrothermograph could verify the fact that "when bodies come into the gallery, the temperature rises." However, Haacke continued to insist human impact was beside the point and that "unless it's really packed, [humans] have no effect on the humidity." Ibd., p. 24, Note 35 . In an email to the author (29.8.2020), Jones noted "condensation is one of those things, like clouds, that changes too slowly really to see any effect of our own presence" and that despite Haacke's continued insistence that bodies did not impact his work, the artist's decision to include a hygrothermograph in another exhibition as a type of conceptual readymade was a "brilliant way to connect the social systems with the 'nature' ones that Hans wanted to foreground." 


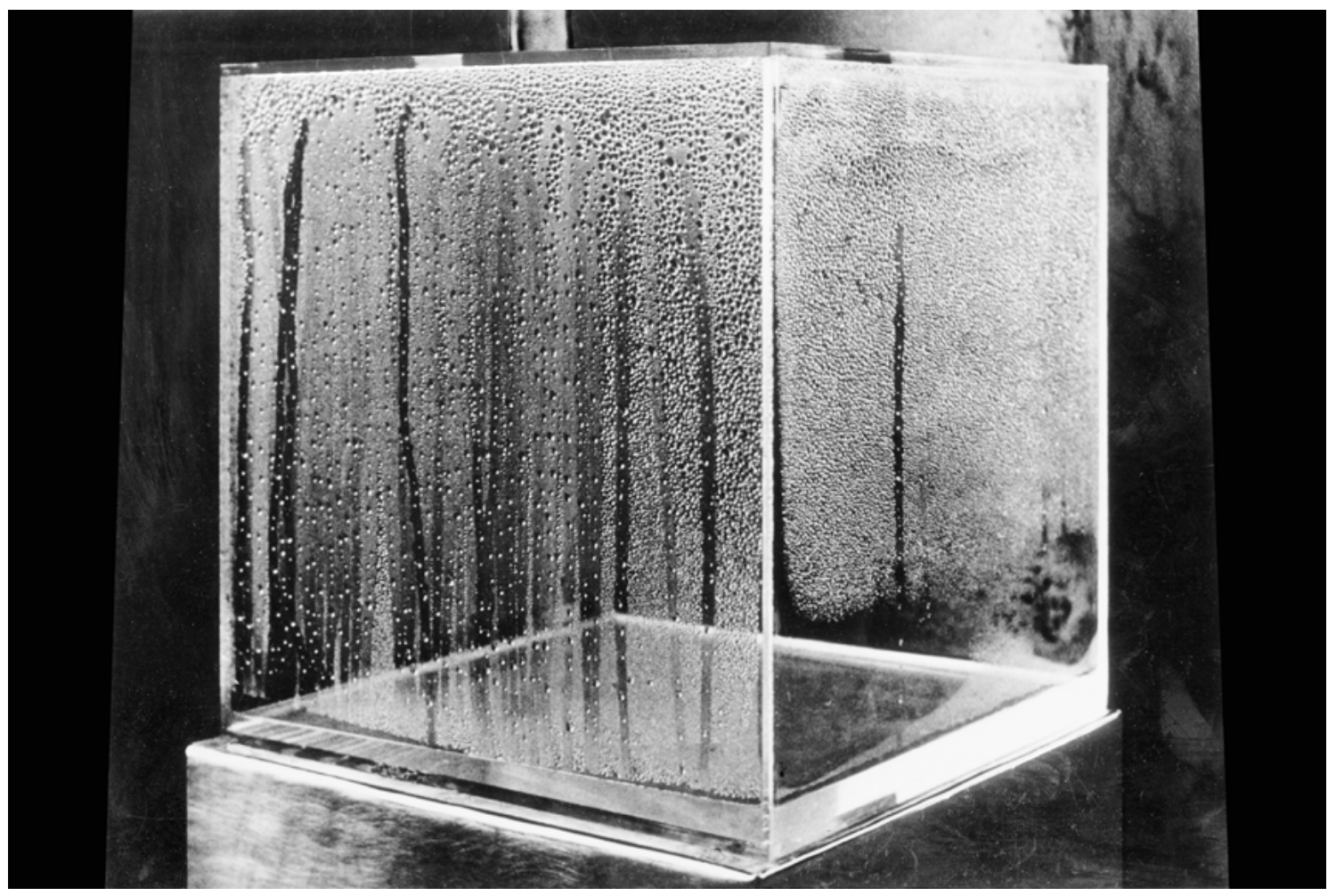

Fig. 1: Hans Haacke, Condensation Cube, 1963-65 Clear acrylic, distilled water, and climate in area of display $30.5 \times 30.5 \times 30.5$ 
been untouched by the visitors, but the "sweat, heat, and vaporous breath"4 of the crowds had a hand in passively shaping its internal processes. Constructed from artificial materials that otherwise had no overt signs of human life meant that in order to perceive the process Haacke wanted the Cube to show, the visitors physically became part of it.

Standing side-by-side, the viewer and the Condensation Cube became two breathing entities that undermine sculpture's conventional subject/object divide. "The process of condensation does not end," wrote Haacke in 1965 when he first publicly exhibited an earlier iteration of Condensation Cube, adding, "[...] the conditions are comparable to a living organism which reacts in a flexible manner to its surroundings." 5 Haacke further nuanced how the conceptual underpinnings of Condensation Cube drew from its material ones. "A sculpture that physically reacts to its environment is no longer regarded as an object," asserted Haacke in 1967, suggesting that it "merges with the environment in a relationship that is better understood as a 'system' of interdependent processes [...] [which] evolve without the viewer's empathy. He becomes a witness. A system is not imagined, it is real." ${ }^{\prime 6}$ However, as Jones surmised, while Haacke may have conceived of these works as operating in her words as "outside standard aesthetic discourses involving emotion, interpretation, culture and memory" remaining "in some measure outside of the human altogether," Haacke's systems still relied on "human agency to set them in motion." In this account, agency here refers to the ways that the viewer's own lived experience conditions a person's ability or facility to move through the exhibition as well as the pragmatic way that human intervention into naturally occurring processes was required to maintain the work of art. As Jones's careful curatorial 2011 re-staging of Condensation Cube at the MIT List Visual Art Center made evident, the inorganic compound copper sulfate had to be used to treat the water inside the cube to curtail the growth of unwanted bacteria, algae and other biota which would have literally clouded the transparency of the entire conceptual operation that Haacke intended to foreground in 1967 - the idea that systems remained "independent of the human."

4 Jones 2011 (note 2), p. 15.

5 Haacke's written description of Condensation Cube is reprinted in the section "Artist Statements" in: exh. cat. Cambridge, Massachusetts 2011 (note 2), pp. 47-53, here: p. 48.

6 Ibd.

7 My reading of Haacke's early kinetic works is informed by Jones's careful 2011 remaking of Haacke's 1967 exhibition for the MIT List Visual Arts Center. This essay has benefited from her revelatory curatorial research and analytical approach to reading Haacke's work, as well as subsequent conversations about Haacke's reception within contemporary art history. See ibd.

8 Ibd., p. 13. Jones characterized this operation as: "the human could watch; the human might even push a system into motion, but the system's unfolding was independent of the human." Ibd., p. 14. 
Despite the artist's profound initial intentions, I would argue, Haacke's Cube foregrounded not only issues of empathy, but also more pointedly complicity. This reading is an attempt to forestall the tendency within art historical discourse to draw a distinct line between Haacke's early kinetic works which purportedly operate outside of the social and his later works which overtly countenanced Institutional Critique. In this estimation, like all of Haacke's early works, Large Condensation Cube operates as a material threshold between two relationally defined domains - a living breathing atmospheric chamber that holds notions of purity and toxicity in precarious balance and an equally volatile and inscrutable social space that introduces metaphors of visibility and difference to a body of work that has otherwise been fastened to real-time "systems." Thus, any claim for a type of unmediated transparency in Haacke's early works remains problematic. If even by the end of the 1960 s, Haacke could still maintain that the viewer was "a witness" rather than an actant - or complicit with the "system," the urgency of the broader political context of the civil rights movement and the rise of a military industrial complex would mitigate this claim of cultural remove. ${ }^{9}$

\section{Art as System}

In fact, just a year after Condensation Cube was first exhibited, Haacke was invited to give the keynote address to the Intersocietal Color Council's annual conference in April 1968 where he declared, "an artist is not an isolated system." ${ }^{10}$ Haacke's nuanced understanding of the chemical make-up and cultural history of his selected materials (the acrylic used to create the Cube was first developed as a glass substitute for military war airplane windshields) combined with his ability to parse complex emerging theories of cybernetics (feedback, command control, and second order Cybernetics) alongside Beaux Arts traditions (rendering, perspectival space) would have made him a natural choice to be a guest speaker at a professional society that sought to unite artists, scientists, designers, and educators to advance the application of color theory within both art and industry. Haacke's instantiation of the term 'system' signaled the shifting definition of visual art during the late

9 Detailing the reception of Haacke's 1967 exhibition at MIT, Jones draws an even more emphatic reference to this paradox noting that "earlier processes seen to 'evolve without the viewer's empathy' at MIT could hardly jibe with a new reality in which the personal had become political." See ibd., p. 23.
10 Hans Haacke, "Untitled Talk at Annual Meeting of Intersocietal Color Council New York, April 1968," in: Alexander Alberro (ed.), Working Conditions: The Writings of Hans Haacke, Cambridge, Massachusetts 2016, pp. 14-25, here: p. 15. 
1960s. No longer an insulated field historically predicated on a narrow set of aesthetic concerns, art works were conceived as active agents what Haacke and especially Clark would refer to as ethical propositions on the material, economic and social contexts in which their artworks were displayed, housed, exchanged and otherwise circulated as part of a larger art world system. The term 'system' also pointed to the ways that artists adapted concepts associated with social systems, real-time systems, alongside mechanical, ecological, and biological ones in an effort to shift the conception of visual art away from its object-oriented origins towards a more transitory process-based future. For Haacke, by 1968 visual art could no longer remain static but had to take on an operational ethos making the implicit connections between the pervasiveness of neo-liberal ideology and the role of cultural production as a conduit of economic and political power more explicitly legible and thus, traceable and, potentially, actionable.

At the same time, Haacke's assertion also acknowledged the impossibility of working outside of the system. Artists, like curators, critics and art historians are imbricated within a patronage structure that is reliant on the intertwined apparatus of state-sponsorship and private investment. Importantly, Haacke's artworks do not offer blanket solutions, but instead critically address art's dependence on commerce by offering a type of radical transparency that exposes the interconnectedness between the so-called public good and private interest. Key to this process is recognizing the structure of systemic bias that undergirds the built spaces and instruments of collection, display and publication which comprise the broader social ecology of art. By this time, Haacke's earlier position of remove or witness, had changed. "Rather than staying aloof [...] artists should speak out against society's attempts to use their work as a means to cover up the failure of tackling urgent issues," Haacke opined during his 1968 Color Council talk, adding that "[s]ponsoring the arts can be an honorable and worthwhile engagement, but it means little when the very basis of human interrelations and physical survival are at stake."11 This sharp logic - the relative value of art to life - has shaped Haacke's five decades-long public record of making nuanced artworks economically employing natural elements (air, seeds, soil, water) in concert with 
consumer materials (acrylic, electric fans, fabric, motors, printers), and repurposed commercial techniques (advertisements, polling data, surveys) in order to make visible a vast machinery that continues to undercut access to social justice as well as any sense of accountability. Art museums have been Haacke's primary subject but his work points to any institution predicated on colonialism which continues to advance the interests of the ruling class while purporting to serve the greater public.

If we accept Haacke's proposition that artworks remain contextual as well as interdependent upon various analytic frameworks (such as gender, occupation, class, nationality, language, 'race') then the seemingly innocuous geometric forms, serial repetitions of materials, and the often muted spaces that characterize his early exhibitions should be read against the rancor of a socio-political backdrop shaped by the ongoing struggle for civil rights and equality in the face of systemic oppression in the 1960s. And importantly, these works are not confined to the past, but continue to play out in the present tense and portend an uneven future. In fact, Haacke's kinetic sculptures made between 1963 and 1972, featured in the 2019 retrospective Hans Haacke: All Connect$e d$, emphasize the transitory nature of their component parts, contextual references, and exhibition histories which have given shape to the art historical discourse on Conceptualism and Institutional Critique. ${ }^{12}$ Less examined is how Haacke's more overtly critical practices synch up with his early systems-based kinetic works. ${ }^{13}$ I would propose that at their best, Haacke's early works trigger a kinetic operation in which conventional museological practice (acts of interpretation, conservation, classification) which institute processes of standardization to convey a false sense of objectivity are revealed to be distinctly human and subject to interruption, failure, breakdowns, and leaks - in both metaphorical and pragmatic terms. For example, despite the sense that artworks are timeless, hermetically sealed, and perfectly preserved, all works of art and especially kinetic ones or those reliant on water, electricity or other fluctuating sources in fact require constant refurbishment, maintenance and monitoring as their mechanisms wear down, their sealants or barriers deteriorate, and their power sources become obsolete. The resulting metaphorical sense of vigilance remains an important tactic

12 This text draws directly from my contribution to the catalogue edited by exhibition co-curators Gary Carrion-Murayari and Massimiliano Gioni. See Gloria Sutton, "Hans Haacke: Works of Art, 1963-1972," in: Hans Haacke: All Connected, exh. cat. New York 2019, pp. 10-16. I want to thank Hans Haacke and Linda Haacke for their generosity of time and spirit in fielding my queries.
13 For a notable exception see John A. Tyson, "Beyond Systems Aesthetics: Politics, Performance, and Para-Sites," in: ibd., pp. 258-264. 
for critical art practice in the present day. As critic Aruna D'Souza underscored in her review of the 2019 exhibition, Haacke's "retrospective provides an invaluable measure of how the artwork has changed since the 1970s and the extent to which the models for critical engagement that Haacke proposed remain viable", concluding: "[T]hough some of Haacke's work examined the activities of individual businessmen and art patrons, the lesson of his practice is that systems are of even greater concern."14 In this way, the concept of systems thinking does not simply emphasize the fact that differences exists, but also discloses the very mechanisms by which those differences are sustained.

\section{Breathing Room}

Reconsidered in the midst of yet another wave of racist killings in the United States including the murders of Ahmaud Arbery, George Floyd, Atatiana Jefferson, Tony McDade, and Breonna Taylor as well as the growing swell of Black Lives Matter protests, Haacke's work prompts another valence on the cognizance of what it means to witness. In particular, social media activists from movements such as @ChangetheMuseum have demanded that museums begin to acknowledge, if not reckon with their complicity with institutional violence and racism casts Haacke's works not only in a different light, but into one that illuminates the racialization of bodies within public space. My point here is not that Haacke's early kinetic artworks are somehow essentially racialized by the artist's own identity, or that the figurative blankness within these works can be read as a type of empty plurality - accommodating or reflecting any and all bodies. Rather it is that the visual and spatial effects of Haacke's early works continue to draw vital attention to the very act of taking up space. As architectural historian Mark Jarzombek notes, "a museum visitor is a potential danger to the law of environmental constancy. If too many people were to stand close to the $C u b e$, the micro climate around it would change the Condensation Cube into a mere plexiglass box, setting off environmental as well as curatorial alarms." 15 Of particular importance, however, is how

14 Aruna D'Souza, “Inside Job," in: Art in America, November 2019, pp. 56-63, available at: https://www.artnews. com/art-in-america/features/hans-haacke-newmuseum-retrospective-institutional-critique-63666, 29.10.2019 (last accessed: 29.6.2020).

15 Jarzombek 2005 (note 1), p. 101. 
different and differently-abled bodies are permitted to move through institutional and public spaces as well as the uneven distribution of resources between cultural bodies and the fragility of breathing room, which always remains conditional. And importantly, public calls for more diverse representation across all ranks of museum leadership including the composition of Boards of Trustees and curatorial departments as well as broadening the communities traditionally served have resulted in the implementation of inclusion programming and anti-discrimination. ${ }^{16}$

Beyond the control and management of bodies in adherence to museological and safety or social distancing protocols, the need for breathing room - i.e. time to prepare or recover from a stressful situation or encounter - produces profound metaphorical associations with those that have been systemically oppressed and whose cultures have been stripped of identity, co-opted and excised from history as Frantz Fanon powerfully observed in Black Skin, White Masks whose English translation in 1967 overlapped with the initial public circulation of Haacke's early works discussed here. While kinetic artworks are typically characterized by their means of mechanization (motors, electricity), Haacke's kinetic artworks physically manifest the act of breathing and the movement of air and, equally, the opposite effect the lack or curtailment of air and breath when the works are shut off. The constriction of physical breath, Fanon maintains, results in the adoption of a type of psychological suffocation - describing these phenomena in A Dying Colonialism (1959/1967) as a type of "observed, an occupied breathing" and "combat breathing." 17 The act of revolt is not in advance of a particular culture, Fanon asserted, it is due to the fact that it becomes "impossible to breathe in more than one sense of the word." 18 This focus on the metaphorical suggestiveness of turning air into breath, and the ways it can flow freely or remain constricted, eschews the rhetorical deployment of these processes simply as visual tropes and avoids using 'air' or 'breath' as thematic categories. Instead, paying concerted attention to the externalization of breath and the act of

16 Such was the case for Boston's Museum of Fine Arts, an august encyclopedic museum like many others throughout the United States that proports to exhibit art from diverse cultures yet was accused of not welcoming diverse audiences. In 2020 the MFA was legally forced to develop policies and training programs that would address systemic racism by the institution. See Zoe Greenberg, "After charges of racism, MFA agrees to create $\$ 500,000$ diversity fund," in: Boston Globe.com, available at: https://www.bostonglobe.com/2020/05/05/ metro/after-charges-racism-mfa-agrees-create-500000diversity-fund, 5.5.2020 (last accessed: 30.8.2020).
17 Frantz Fanon, A Dying Colonialism, translated from the French by Haakon Chevalier, New York 1967 [fr. 1959], p. 65.

18 Frantz Fanon, Black Skin, White Masks, translated from the French by Charles Lam Markmann, New York 2008 [fr. 1952], p. 201. 
breathing offers a phenomenological mediation that can supersede art's reliance on visual or optical cues. Here, the kinetic can register as palpable.

Produced explicitly for public display at their outset, Haacke's now canonical kinetic sculptural artworks introduced self-contained real-time systems that interfaced with their institutional hosts - museums, galleries, and the built environment - to make visible often invisible yet pestilential forces. The consequences or fallout from pollution and social inequity - to name two such crises central to Haacke's work - often circulate below the surface until the buildup of toxins and chronic pain precipitates the breakdown of bodies..$^{19}$ Haacke's works discussed here first circulated under the immediate shadow of Dr. Martin Luther King Jr's assassination in 1968 and continue to be viewed 'in the wake' of sustained systemic violence and institutional racism that defines what literary scholar Christina Sharpe trenchantly terms "the carceral continuum of black life," a forceful expression for the "violence everywhere and everyday enacted by the state on black people. ${ }^{20}$ Additionally, starting in 2020 the "hashtag activism" of @ChangetheMuseum amplified the voices of marginalized groups and BIPOC (Black, Indigenous, and People of Color) long excluded from and underrepresented within elite spaces such as art museums. The Instagram Account not only allowed people to report, but importantly, to also corroborate the pervasive prejudicial hiring, promotion and collection practices of art museums that has previously gone unchecked. While curatorial leadership at New York's Guggenheim and San Francisco Museum of Modern Art were expressly singled out for redress by @ChangetheMuseum, the collective airing of racist incidents at a range of institutions prevented singular accounts from being discredit-ed as isolated or dismissed as fabrications. This collective public accounting exerted unprecedented

19 For an extended explication of how racism is considered a public health crisis see the research and policy analysis done by the Pew Trust: Christine Vestal, "Racism Is a Public Health Crisis, Say Cities and Counties," in: Pewtrusts.org, available online at: https://www. pewtrusts.org/en/research-and-analysis/blogs/ stateline/2020/06/15/racism-is-a-public-health-crisissay-cities-and-counties, 15.6.2020 (last accessed: 1.6.2020).
20 Christina Sharpe from "Black Life, Annotated," in: New Inquiry, 8.8.2014, quoted in Darby English, To Describe a Life: Notes from the Intersection of Art and Race Terror, New Haven 2019, p. 1. The term "in the wake" is drawn from Sharpe's urgent account of the intersection of art, activism and racism. See Christina Sharpe, In the Wake: On Blackness and Being, Durham, North Carolina 2016. Sharpe's term expands upon Fanon's earlier description of how colonization precludes the notion of a generative world view. "The colonized person, in this respect is like the men in underdeveloped countries or the disinherited in all parts of the world, perceives life not as a flowering or a development of an essential productiveness, but as a permanent struggle against an omnipresent death. This ever-menacing death is experienced as endemic famine, unemployment, a high mortality rate, an inferiority complex and the absence of hope for the future." Fanon quoted by Adolfo Gilly in the introduction to Fanon 1967 (note 17), p. 14. 
pressure on all contemporary art museums to re-examine their often boiler plate statements on advancing diversity within their ranks. ${ }^{21}$ In this light, the collective charge was not simply for museums to represent a plurality of diverse bodies in a particular space but to be aware of the institutional structures art is complicit with and to enact systemic change. As art historian Darby English compellingly elucidated in How to See a Work of Art in Total Darkness (2008), Haacke's work precisely draws attention to "the constitutive outsides of institutions of art, insinuating 'live' politics in sites where, if it manifests at all, it does so as archived (valorized) or deadened, or streamlined into celebrations of difference for its own sake (theatricalized)," adding that Haacke operates on the "theoretical premise that, as cultural authorities vested to represent the past to the present and the present to itself, these institutions [museums] purchase their authority at the very real costs to the variously constituted publics they ostensibly serve." ${ }^{22}$

\section{Active Users}

The aim of reexamining these artworks from the 60 s in the current moment is not out of a sense of return, nostalgia or a desire "to retrieve the memory of a period that functions in the Left imaginary as the 'last' era of social justice on a broad scale, a ground zero of progressive politics," as art historian and curator James Meyer's notes in Art of the Return - his analysis of contemporary art's frequent engagement with the long 60s. Instead, as Meyer urges, we view the period in all its complexities and contradictions. ${ }^{23}$ In this case, looking at the 1960 s through Haacke's works allows us to see a period in which media technology unevenly expanded public discourse while also becoming an instrument of social control. In the United States, a growing militaryindustrial complex suffocated and syphoned off social service resources

21 Emerging in 2011, the term "\#hashtag activism" refers to the coordinated efforts by historically disenfranchised populations to use Twitter to build a network of dissent. See Sarah Jackson/Moya Bailey/Brooke Foucault Welles, \#Hashtag Activism: Networks of Race and Gender Justice, Cambridge, Massachusetts 2020. For an account of how @ChangetheMuseum forced SFMoMA to publicly address issues of diversity and inclusion within its staff see Carol Pogash, "Its Top Curator Gone, SFMoMA Reviews Its Record on Race," in: The New York Times. com, available at: https://www.nytimes.com/2020/07/22/ arts/design/sfmoma-gary-garrels-resignation.html, 22.7.2020 (last accessed: 25.8.2020). Regarding Guggenheim's "expanded diversity effort" in response to the public online statement "A Better Guggenheim" signed by over a 100 current and former staff members detailing how the museum cultivated "a culture of institutional racism" see Zachary Small, "Guggenheim Approves Diversity Plan After Staff Complaints of Racism," in: The New
York Times.com, available at: https://www.nytimes. com/2020/08/17/arts/design/guggenheim-diversityplan-racism.html, 17.8.2020 (last accessed: 25.8.2020).

22 Darby English, How to See a Work of Art in Total Darkness, Cambridge, Massachusetts 2008, p. 147.

23 James Meyer, The Art of Return: The Sixties and Contemporary Culture, Chicago 2019, p. 11. 
in the immediate post-war period paving the way for the broad acceptance of a coercive management style associated with the rise of the digital computing economy that has become entrenched over the past fifty years. By the time of Haacke's retrospective in the fall of 2019, the Habermasian public sphere was no longer recognizable having long been reshaped by the habits of online commerce and social media where the civil disobedience and grassroots activism of the 1960s have been overtaken by the tech industry's rhetoric of 'disruption' and the cultivation of citizens not only as consumers but as 'active users.' Community within the neo-liberal context now refers to a customer base rather than a polis. During the 1960 s, as communications scholar Fred Turner explains, "the same military industrial research world that brought forth nuclear weapons - and computers - also gave rise to a free-wheeling, interdisciplinary and highly entrepreneurial style of work." ${ }^{4}$ In fact, the specific media technologies developed to assist with the management and maintenance of such monolithic systems of authority since the 1960s including video and the ensuing practice of recording and surveillance, audio and video playback as well as image storage abilities and most expansively, the onset of networked digital computing prompted artists to invent new critical models with which to structure and frame their practice. This type of systems thinking within visual art was marked by the signal 1968 exhibition Cybernetic Serendipity: The Computer and the Arts curated by Jasia Reichardt at the Institute of Contemporary Arts, London followed by Kynaston McShine's Information exhibition at the Museum of Modern Art (MoMA) in 1970, the same year that Jack Burnham mounted the exhibition Software a few blocks north on Manhattan's Upper East Side at the Jewish Museum. As Haacke's own prolific body of work attests, starting in the late 1960s organizational functions and administrative terms such as data, information, statistics, documentation, and research - terms meant to quantify rather than qualify lived experience - comingled with art's essential vocabulary of form, color and representation.

\section{From Air to Breath}

And paradoxically, while the surge in technology-driven artworks and exhibitions between 1968 and 1970 may have portended our current

24 Fred Turner, From Counterculture to Cyberculture: Stewart Brand, the Whole Earth Network, and the Rise of Digital Utopianism, Chicago 2006, p. 4. 
technocratic digital present, curator Willoughby Sharp argued the turn toward media technology during this pivotal period also provoked a renewed interest in analogue elements - air, water, earth and fire. And importantly, the ability for these elements to activate sensorial perceptions including sound, touch and breath over purely visual ones. "[T]he most successful work of the near future will be kinetic in content, immaterial in nature, disposable in substance, uncommercial in attitude, and environmental in effect," wrote Sharp in the introductory text to a less studied, but no less influential 1968 exhibition entitled Air Art. ${ }^{25}$ Compared to the other more storied art and technology exhibitions mentioned earlier, Air Art traveled to student-focused, regional venues throughout the United States. Sharp's curatorial premise was not simply anti-technology, or pro-environment. Instead it suggested a more interdependent relationship between the two as reflected in Sharp's reference to Marshall McLuhan for the catalogue's epigraph: "The new media are not bridges between man and nature; they are nature" drawing on ideas advanced in the Canadian media theorist's influential 1964 volume Understanding Media: The Extensions of Man. ${ }^{26}$ The exhibition and the term 'Air Art' became a way to link disparate artistic practices that coalesced around the novel use of air as both mechanically produced (pneumatic and compressed) as well as air processed through the body as breath (balloons and smoke). Drawing on the lineage of a Western European Avant Garde art history, Sharp's curatorial statement cited Marcel Duchamp's glass ampule, 50cc of Paris Air (1919), black and white photographs showing László Moholy-Nagy elevating a metal chisel in midair using a compressed air hose (1940) and the quasi-conceptual provocations of Yves Klein who hurled his own body from buildings in an act of 'Air Architecture' (1960) as foundational touchstones for the kinetic experiments of Les Levine, the pneumatic balloons of Piero Manzoni, and the hand-painted fabric air pillows of Akira Kanayama as well as Andy Warhol's silver helium balloons. Additionally, in Sharp's estimation, as the next logical extension of kinetic art, Air Art shifted away from the mechanistic focus on gears, resistors, circuits, blowers and capacitators, and gave space to more diffuse esoteric ideas of human connectivity and social respon-

25 Willoughby Sharp, “Air Art”, in: Air Art, exh. cat., YM/YWHA Arts Council, Philadelphia, Pennsylvania, New York 1968, pp. 4-11, here: p. 11. In addition to Haacke, the exhibition featured works by Architectural Association Group, Akira Kanayama, Les Levine, Preston McClanahan, David Medalla, Robert Morris, Marcello Salvadori, Graham Stevens, John Van Saun, and Andy Warhol. The exhibition traveled to the YM/YMHA in Philadelphia in March 1968;
Cincinnati's Contemporary Arts Center in April-May 1968 The Lakeview Center for the Arts and Sciences in Peoria, Illinois in June 1968 and moved to University of California Berkeley's University Art Museum in January 1969 and its final venue was the Lamont Gallery at The Phillips Exeter Academy in March 1969.

26 lbd., p. 13. 


\section{Gloria Sutton}

The Politics of Breath: Reanimating the Air Art of Hans Haacke and Lygia Clark as Models of Social Critique

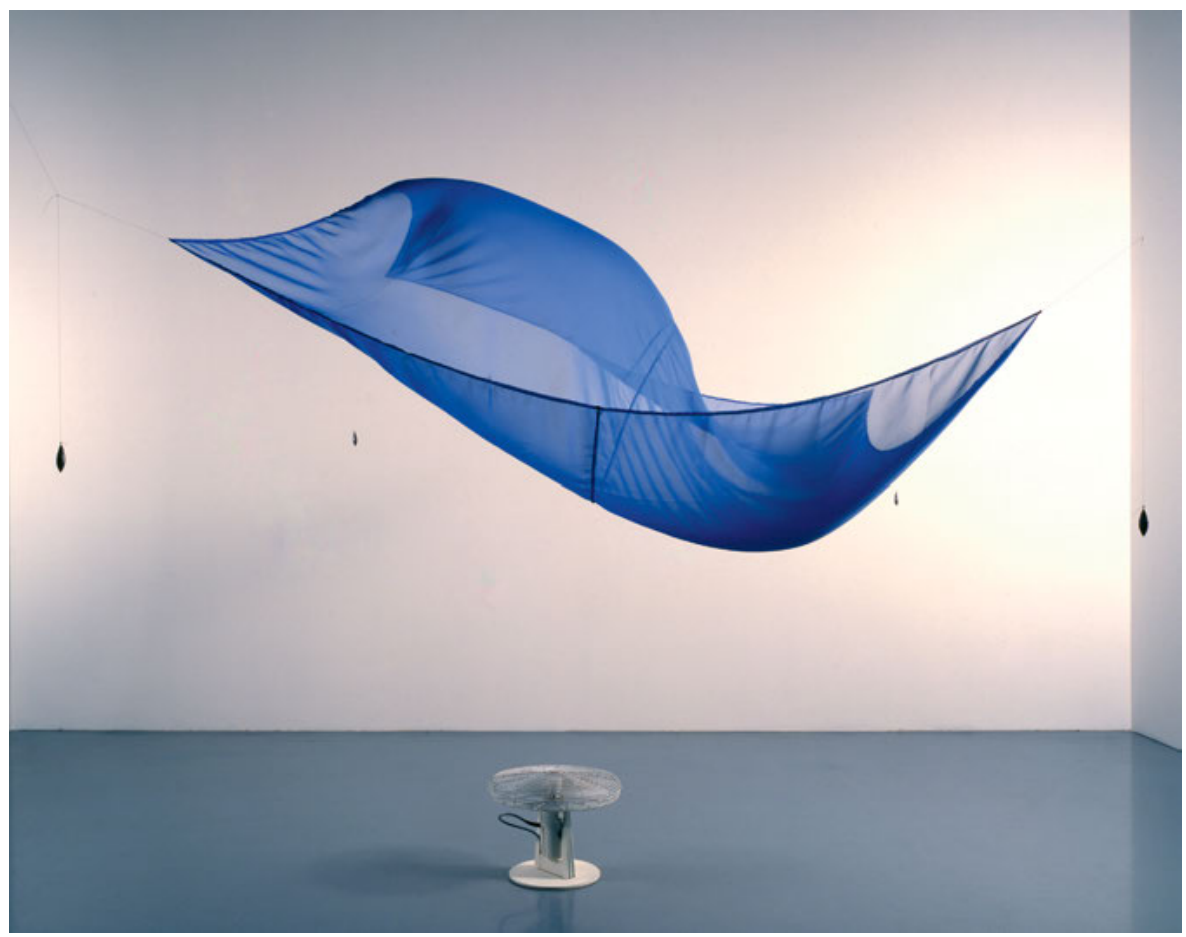

Fig. 2: Hans Haacke, Blue Sail, 1964-65, chiffon, oscillating fan, fishing weights and thread, dimensions variable 
siveness - what could be considered the politics of air and breath in visual art. Air - both vital and fleeting made generative allusions between machines functioning like bodies - and bodies operating as machines. Sharp stresses qualities of precarity and ephemerality undercutting art history's dedication to acts of preservation and memorialization.

While Haacke's Skyline, a fourteen-hundred-foot string of simple white helium balloons was pictured on the cover of Air Art's catalogue, his kinetic sculpture Narrow White Flow (1967-1968) was installed inside the gallery space. Representative of the way Haacke used simple electric fans to generate volumetric forms, the artist anchored a rectangular swatch of white silken fabric to the gallery's corner and when the fan was switched on, forced air transformed the lifeless cloth into an animated current. Here, air becomes the breath of life. Narrow White Flow developed directly from a series of earlier works that foregrounded how breath is a measure of vitality which can be extinguished in an instant. Sphere in Oblique Air Jet (1964-67/2011) and Flight (version 1, 1965-66, and version 2, 1967/2011), for example, follow the fluid dynamics of Bernoulli's principle, which describes the fluctuating relationship between the pressure of moving fluid (air and water) and its velocity or speed to explain how solids can take flight or the inverse, fall or fail to even leave the ground. Deploying a floor-mounted electrical fan to generate an upward stream of air, these works suspend a balloon or a silk parachute, respectively, in a precarious dance choreographed by the laws of physics. Offering a horizontal complement to these vertically oriented works, Haacke devised Blue Sail (1964-65), in which a square swath of blue chiffon is suspended from its four corners with nylon thread and fishing weights above an oscillating fan (Fig. 2). In Haacke's description, the motor's force "determines whether the fabric is given life and breathes." 27 And we can assume its corollary - when switched off, air is denied, and the cloth falls flat. Importantly, these works have never hinged on technological novelty. As Sharp's Air Art exhibition underscores, Haacke's works may assume the scalar conditions of physics: amplitude, time, force, duration - but as living, breathing works, they also function as descriptors for corporeal experiences. Additionally, these works amplify the precarity of air as breath 
- an act elemental to life, yet thought of more when blocked, constricted or deprived.

Regardless of its source - human or machinic - it was the ability for air to create open space that was important to art historian Peter Selz, then the Director of University of California Berkeley Art Museum, who noted in the catalogue's preface: "[A]s our atmosphere becomes the material of art, [...] our motion through it establishes the form of art." 28 While Selz's intention was undoubtedly less prescriptively aspirational, I do want to suggest that an exhibition dedicated to air emphasizes not only the very nature of the way that bodies move through space, but also the possibility that another type of ingression of public space can take shape. It might foster the acts of venting - literally airing out grievances, complaints, calling out transgressions while also creating space for others to do so as well without harboring a monolithic vision of a singular body that moves in unison, nor hews to the dictates of a standard presentational strategy.

\section{Public Venting}

The act of venting is precisely the critical nexus between Haacke and Jammie Holmes' 2020 "Aerial Demonstrations". Holmes printed George Floyd's last words on airplane banners which were flown over Detroit, Miami, Los Angeles, and New York on May 30th 2020 - connecting the specificity of Floyd's murder by the Minneapolis Police with other sites of violence against Black and Brown bodies across the United States (Fig. 3). Among these was a banner reading "Please I Can't Breathe" from Floyd's harrowing final moments on May 25th 2020 gasping for air as his life was slowly being extinguished by the police. ${ }^{29}$ The murder was recorded on numerous sources (CCTV security cameras and body cameras worn by police and emergency medical technicians) and transmitted through both mass and social media. By taking to the sky, Holmes' demonstration moved beyond geographic confines, suggesting that a seemingly isolated occurrence of police brutality, in fact, is an episode within a longer-term continual systemic crisis, laid out for all to witness. Holmes reclaimed a form of direct address typically used for

28 Peter Selz, “Acknowledgements," in: exh. cat. New York 1968 (note 25), p. 4.
29 For an account of Jammie Holmes's 2020 "Aerial Demonstrations" see Hilary Moss, "George Floyd's Final Words, Written in the Sky," available at: The New York Times.com, https://www.nytimes.com/2020/06/01 /t-magazine/george-floyd-jammie-holmes-artist.html, 1.6.2020 (last accessed: 4.8.2020). Additionally, refer to the artist's web platform for additional documentation and links to the artist's efforts to support social justice advocacy work: https://www.jammieholmes.com/ theyre-going-to-kill-me (last accessed: 14.8.2020). 
PLEASE I CAN T BREATHE

Fig. 3: Jammie Holmes, Please I Can't Breathe, Detroit, 2020, Aerial Demonstration from the project They're Going to Kill Me

(Detroit), 2020 


\section{Gloria Sutton}

The Politics of Breath: Reanimating the Air Art of Hans Haacke and Lygia Clark as Models of Social Critique

\section{6}

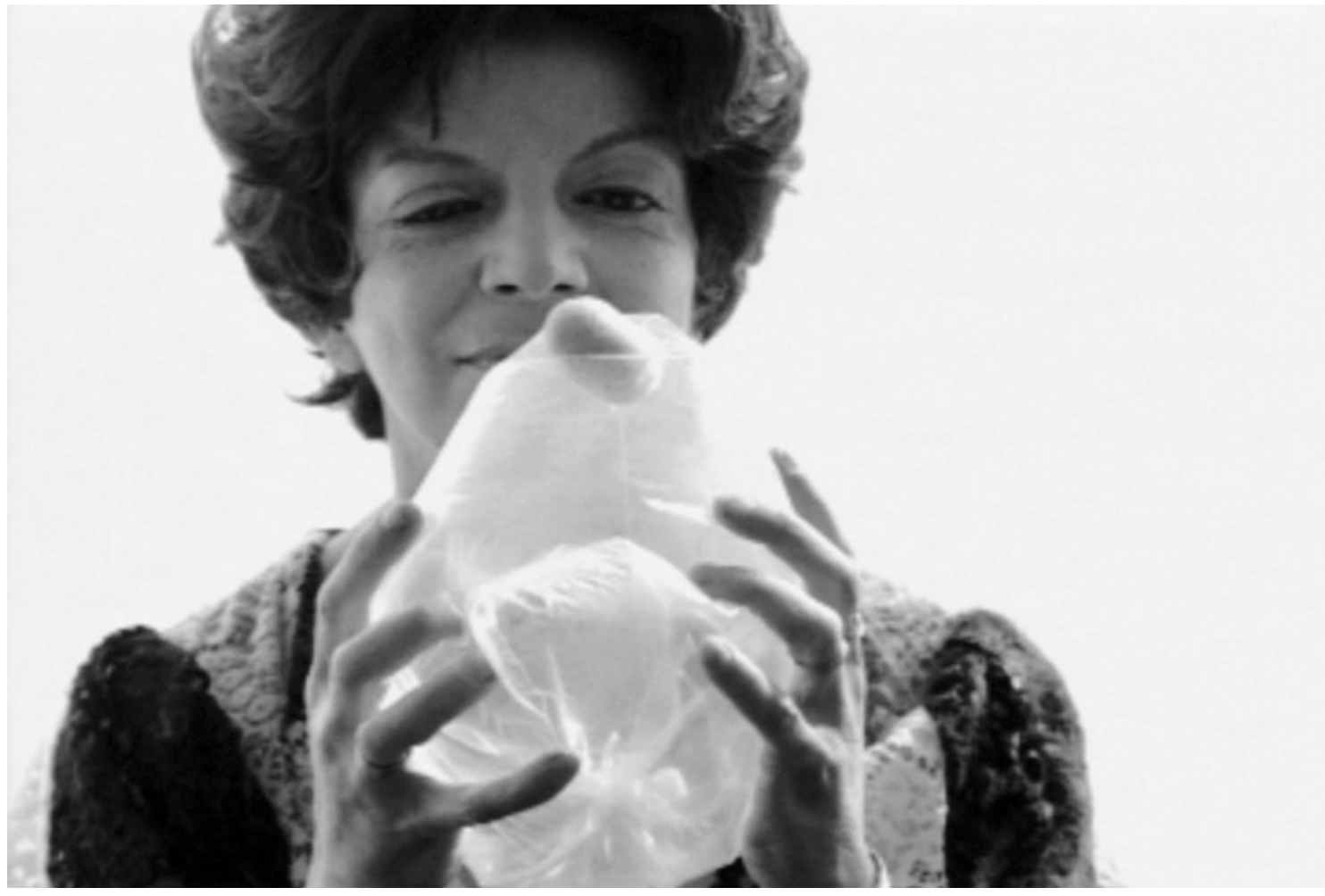

Fig. 4: Lygia Clark, Pedra e ar (Stone and Air), stone and plastic bag, 1966, variable dimensions 
advertisements not to promote, but as the title proclaims - to demonstrate - to signal revolt because as Fanon notes, that is what happens when you can no longer breathe. For the viewers who encountered Holmes's transcription of Floyd's fleeting words staring up at the sky while on vacation at the beach or driving to work in their cars, the question is not only: Do black lives matter?, but: Does the act of bearing witness also make the viewer complicit with a system of oppression and disavowal?

\section{Comparative Systems}

The hindrance of breath within systems of oppression is not only a central theme in contemporary social justice art practices but also to Lygia Clark's kinetic works from the period of Haacke's early systems. They also have to be read in the context of a spectatorial shift in the contemporary art field more broadly - leading to a type of intersubjective exchange between forms, bodies, and other organisms. Based in Rio de Janiero and Paris during the 1960s, Clark's progressive assault on the bounded, autonomous art object moved from tracing what she called the "organic line." Employing modulated, incised painted surfaces to generate geometric abstract paintings during the 1950s, Clark transitioned into applying organic materials (water, fluids, strings) directly to the body of the participant to create what she called Arquiteturas biológicas (Biological architectures) as well as Objetos relacionais (Relational objects) during the $1960 \mathrm{~s} .{ }^{30}$ Foundational to international modernism, the 2014 MoMA exhibition was the first comprehensive North American presentation introducing the expansiveness of Clark's critical thinking and her singular advancement of engaging viewers as participatory collaborators.

Having emerged during the 1950s in association with Grupo Frente (alongside artists Hélio Oiticica, Lygia Pape and others) which advanced Neo-Concretism, Clark began to explore the political ramifications of animating inanimate materials around 1959, when she began producing metal tabletop sculptures that she referred to as Bichos (creatures, small beasts). These maquettes which first assumed the scale of the hand, then of the body, remained malleable, their hinged plates could be folded and unfolded by the spectator in a variety of multiplicities. "Instead of

30 For a detailed reading of how Clark's activation of the "organic line" shifts from a graphic tool which enfolded European Modernism's utopian aims with a distinctly Brazilian Avant Garde strategy, see Irene V. Small, Hélio Oiticica: Folding the Frame, Chicago 2016, pp. 33f. 
the form emerging from the inside outward, as the artistic imaginary had so often told the story of sculpture's origins," art historian Briony Fer characterized the way that Clark's works broke down entrenched distinctions between inside and outside as a "response to the actions of the body making it, and by extension those of the body that would end up handling it." ${ }^{31}$ Like Haacke's use of air, Clark's malleable structures were always on the verge of collapse offering a complex and poetic definition of agency and interchange which emphatically critiqued art's mandate to adhere to fixed forms. Moreover, Clark's Sensorial Objects of the 1960s incorporated everyday found materials including shells, wire, string, rubber tubing, plastic bags, stones to enact precarious exchanges between inanimate forms and breathing bodies. ${ }^{32}$ And importantly, for both artists - these gestures were only activated through an intimate encounter with the public.

Clark's 1966 proposition Respire comigo (Breathe with $\mathrm{Me}$ ), for example, asks the user to place one end of a pliable rubber tube, like that of a snorkel which curves to fit one's mouth and breathe underwater - into itself so that the hose forms a closed loop. Tugging and stretching the length of plastic conduit forces air to move through the passageway in a belabored manner that generates the sound of lungs working through respiratory distress. Likewise, in Pedra e ar (Stone and Air, 1973), Clark asked participants to blow into small translucent plastic bags sealing their own breath inside with rubber bands and balancing stones on the rounded corners (Fig 4). Held between the hands, the pressure applied on the volumetric form seemingly created a pattern of rhythmic inhalations and exhalations that shifted the position of the stone with each breath. The force of the air changed the shape and thus the role of the bag - shifting from buffering and protecting the stone (itself a metonym for the body) like a fragile egg in a nest or launching it like a projectile. With their direct connections to apparatuses of breathing, Clark's Sensorial Objects become poignant metaphors for the duality of breath in the body as both a source of animation as well as its vulnerability to control, constriction and suffocation. However, it was the revolutionary potential of activating individual sensual perception in the face of Brazil's repressive military dictatorship that politically

31 Briony Fer, "Lygia Clark and the Problem of Art," in: Cornelia Butler/Luis Pérez-Oramas (eds.), Lygia Clark: The Abandonment of Art, New York 2014, pp. 222-231, here: p. 225.
32 For a nuanced reading of Clark's use of everyday objects and quotidian gestures in relation to concepts of embodiment and viewer participation, see Susan Best, Visualizing Feeling: Affect and the Feminine Avant-Garde, London 2011, pp. 47-66. See also Linn Burchert, "Inspiration und Exspiration. Atemsteuerung in künstlerischen Praktiken seit 1900," Ästhetische Fremdbestimmung (=Kritische Berichte 3, 2019), eds. Katja Müller-Helle/ Julian Blunk, pp. 44-55. 
charged Clark's work. As performance scholar André Lepecki suggests, "for Clark, intersubjective exchange creates above all not communication but a processual, immanent, and unfolding geometry within which the collective and anonymous production of 'circuit-breakers' against micro-fascist control (including micro-fascist self-control) can take place." 33 Between 1968 and 1976, Clark fled the state-sponsored terrorism of her native country Brazil and returned to Paris where she taught a course on gestural communication at the Sorbonne, which precipitated a shift from her individual efforts towards group activities including conducting workshops - a pathway that according to curator Cornelia Butler, would lead Clark to "abandon conventional art making" and shift "into a transdisciplinarity that we might today think of as social practice." ${ }^{34}$ Ultimately, Clark's "abandonment of art" was a manifestation of her critical purview of the institutions that stored, defined and validated certain practices, while leaving others - such as her own - subject to failure.

\section{System Failure}

Haacke, too, developed an equivocal approach to 'systems aesthetics,' deeming it too complicit with the political systems that proliferated the Vietnam War, gender discrimination and racial violence in the United States. System theory with its claims of universality and expansiveness became a constrictive instrument of the patriarchy, government bureaucracy, and the military-industrial complex (collectively referred to as 'the system'). ${ }^{35}$ In fact, the assassination of Dr. Martin Luther King Jr. on April 4th 1968, one week prior to Haacke's lecture at the 1968 Color Council conference, compelled the artist to somberly state, "[1]ast week, Western society, which likes to consider itself civilized, committed another shameful act, providing hideous proof of how great the gap is between this society's cherished self-esteem and reality." 36 Haacke's assessment that "[t]his follows a well-established course. The atrocities committed and condoned in Vietnam and rampant racism at home are only the latest despicable examples of a long tradition. Hardly any Western nation can claim to have had no part in this," continues to bear itself out in 2020. In 1968 in front of a professional

33 André Lepecki, “Geometry, Immanent Acts: Lygia Clark and Performance," in: Cornelia Butler/Luis Pérez-Oramas (eds.), Lygia Clark: The Abandonment of Art, New York 2014, pp. 278-293, here: p. 282.

34 Cornelia Butler, "Lygia Clark: A Space to Open Time," in: ibd., pp. 12-29, here: p. 25.
35 For a nuanced reading of how Cybernetics intersected with the U.S. military industrial complex and its subsequent influence on post-WWII visual art practice, see Pamela M. Lee, Chronophobia: On Time in the Art of the 1960s, Cambridge, Massachusetts, 2004, pp. $62 \mathrm{f}$. 36 Hans Haacke quoted in: Alberro 2016 (note 10), p. 14. 
body dedicated to advancing new thinking about the impact of color on art and industry, Haacke raised the specter of what English calls the "'cultural logic' of color" reminding us that "the most sophisticated modern theories of color never faced facts about color's most consequential worldly impact, namely the spheres of race and racialized (and putatively nonracialized) existences." ${ }^{37}$ A few days after his 1968 talk at the Intersocietal Color Council, Haacke decried the inefficacy of art as an instrument of social change writing in a letter to Burnham: "Art is utterly unsuited as a political tool. No cop will be kept from shooting a black [sic] by all the light-environments in the world." 38

Thus by 1968, Haacke aired his discontent with art's mere potential 'to witness' - understanding that art is complicit with systemic injustice that makes certain people live in constant risk of suffocation, if not worse. The fact that Haacke's artworks remain a futile instrument to halt the way that historical hate schemes are continuously drawn upon, updated and expanded by those in power does not evacuate art's political potential. As ephemeral works that have to be remade each time they are exhibited, both Haacke and Clark's artworks remain iterative and constantly at work avoiding "a retrospective imagination" or a type of "nostalgia that induces a longing to have been present at an event that we have missed." ${ }^{39}$ Rather than a 'witness' to a closed system as Haacke initially claimed in the 1960s, his kinetic works as well as those of Clark's are always reanimated in the present offering a means to rethink how breathing bodies move through air and space becoming untethered from a monolithic past to act on our complex present.

37 English 2008 (see note 22), p. 81. Specifically, English is referring to Ludwig Wittgenstein's Remarks on Colour (1951) as foundational text on color theory that has been a source in art and design education.

38 Haacke quoted from a letter written to Jack Burnham dated April 28, 1968 published in: Jack Burnham, "Steps in the Formulation of Real-Time Political Art," in: Kaspar Koenig (ed.), Hans Haacke: Framing and Being Framed: 7 Works 1970-75, New York 1975, pp. 127-143, here: p. 130.
39 Meyer 2019 (see note 23), p. 259. 